\title{
O Jovem 'Sem Qualidades' e o Desejo de Fascismo: enlaces entre psicanálise, educação e política
}

\begin{abstract}
Rose Gurski'
Cláudia Maria Perrone'

'Universidade Federal do Rio Grande do Sul (UFRGS), Porto Alegre/RS - Brasil

RESUMO - O Jovem 'Sem Qualidades' e o Desejo de Fascismo: enlaces entre psicanálise, educação e política. Este artigo realiza uma leitura sobre a construção da adolescência que vive atmosferas sociais totalitárias, através da análise das variáveis sócio-políticas presentes no romance de formação O Jovem Törless, de Robert Musil. Na interlocução entre psicanálise, educação e política, articulamos a inquietação do autor ante a ambivalência moral de sua geração, com as propostas educacionais e políticas apresentadas aos jovens deste tempo. No romance, a noção de formação foi corroída na Modernidade e substituída pela socialização com práticas homogeneizantes e massificadoras. Diante da adolescência sem qualidades, cabe um trabalho de restauração do desejo, forjando uma versão singular do destino do corpo político do sujeito e do social.

Palavras-chave: Psicanálise e Educação. Política. Adolescência. Desejo de Fascismo. Törless.
\end{abstract}

ABSTRACT - Youth 'Without Qualities' and the Desire for Fascism: links between psychoanalysis, education and politics. This article presents a reading about the construction of adolescence that experiences totalitarian social atmospheres through the analysis of socio-political variables present in the coming-of-age novel Young Törless, by Robert Musil. In this dialogue between psychoanalysis, education and politics, we articulate the author's concern about the moral ambivalence of his generation, with the educational and political proposals presented to the youth of our time. In the novel, the notion of formation was eroded in Modernity and replaced by socialization with homogenizing and massifying practices. In the face of adolescence without qualities, it is necessary to restore desire, forging a unique version of the fate of the subject's political body and society.

Keywords: Psychoanalysis and Education. Politics. Adolescence. Desire for Fascism. Törless.

Educação \& Realidade, Porto Alegre, v. 46, n. 1, e109161, 2021. 
Neste artigo, realizamos um exercício de leitura sobre os efeitos políticos na constituição de jovens de nosso tempo através da leitura das condições sociais e políticas presentes no romance de formação $O$ Jovem Törless ${ }^{1}$, de Robert Musil (2003). Pela via da interlocução entre psicanálise, educação e política, queremos conhecer um pouco melhor o cenário social, cultural e político responsável pela edificação da sociedade austríaca que vivia um intenso vazio, uma espécie de anomia nos anos iniciais do século XX. Tal estado foi traduzido pela expressão sem qualidades, que dá título ao livro seguinte de Musil (1989), O homem sem qualidades. A proposta dessa aproximação reside na percepção de que muitas das condições vividas pelos adolescentes do internato austríaco, onde se passa a história do adolescente Törless, são próximas das condições com as quais os adolescentes de nosso tempo se encontram.

$\mathrm{O}$ mundo com qualidades que produz o homem sem qualidades, de Musil $^{2}$, mostra muitas articulações com o nosso presente. Na narrativa do romance, repleta de questões autobiográficas, o autor pormenoriza toda a sua inquietação com a ambivalência moral que abateu a geração austríaca dos primeiros anos do século XX. Conforme assinala Michael Hanke (2004), Musil descreve um estado da sociedade em que desparecem os padrões normativos de conduta e de crença, em que o indivíduo, em conflito íntimo, encontra dificuldade para conformar-se às contraditórias exigências das normas sociais.

Pensamos que, na atualidade, essa ausência de qualidades se constrói pelos efeitos dos discursos de ódio, do negacionismo da história e da não elaboração de experiências traumáticas - tais como nosso passado autoritário e militarizado -, que, uma vez não simbolizadas, retornam na forma de compulsão à repetição. Desse modo, as situações de violência podem apresentar-se como mais devastadoras ainda porquanto desgarradas de suas condições de produção social, como se vivêssemos uma intrusão do passado no presente - situação que nos coloca perante a um futuro assemelhado a um eterno retorno de eventos já vivenciados.

Os operadores de análise aqui presentes fazem parte de uma pesquisa maior sobre o que temos chamado de desejo de fascismo (Gambetti, 2019; Perrone; Gurski; Gambetti, 2019; Gurski; Perrone, 2020). A professora de teoria política da Universidade de Bogaçizi, Zeynep Gambetti (2019), trabalha com a hipótese de que estamos diante de um novo tipo de fascismo associado com o neoliberalismo. O novo fascismo seria um fenômeno global que não possui características homogêneas. Trata-se de uma mistura de nacionalismo, xenofobia, racismo, lideranças carismáticas, identitarismo reacionário e políticas antiglobalização regressivas, que podem assumir diferentes vestes e que afrouxam naturalmente os vínculos de solidariedade e compartilhamento entre os sujeitos, produzindo efeitos nocivos para a vida em comunidade. Nessa direção, o desejo de fascismo viria como uma interrogação de por que as massas no Brasil não apenas suportam a opressão do fascismo, mas parecem ter uma espécie de fascinação por premissas desse regime político. 
No que se refere aos novos fascismos, observamos, no Brasil, o fortalecimento político da extrema-direita através de bandeiras como o revisionismo histórico e o negacionismo. Gambetti (2019) agrega a este cenário atual, do qual o Brasil não é o único signatário, o impacto da financeirização do mundo pela via de práticas neoliberais selvagens, questão que não se reduz somente aos efeitos econômicos, manifestando-se também no individualismo extremo que se alastra em diferentes âmbitos da vida social.

Entendemos que a psicanálise pode contribuir com este debate explorando a noção de desejo de fascismo a partir da reflexão sobre o limiar crítico das fantasias inconscientes, considerando o quanto elas determinam materialmente nosso imaginário e as condições de nossa realidade. Acreditamos que o desejo de fascismo é relativo ao gozo que se apresenta como empuxo em direção à totalidade, um gozo que busca fazer Um do Outro, criando uma espécie de antilaço social. Esse elemento marcante, de ordem simbólica, incita o gozo com a segregação e destruição do outro, algo que se apresenta nos laços que constituem o dia a dia de Törless, nos internatos alemães e austríacos militarizados do início do século XX, quanto em situações contemporâneas a nós.

É importante sublinhar que tomamos o romance de formação de Musil não exatamente por seu lugar no cânone literário, mas pelos sistemas simbólicos que se evidenciam na obra, especialmente o tecido social conflitante da época. Entendemos como relevante nos remetermos de forma especial às discussões sobre os efeitos políticos da educação e formação social de jovens em meio aos conflitos presentes no romance de Musil, porque tanto a Alemanha quanto a Áustria foram nações centrais para a explosão da sociedade sem qualidades das primeiras décadas do século XX, em que se constituiu o despertar da primavera $^{3}$ de adolescentes como Törless e onde se teceram as condições para a explosão das práticas presentes nas grandes guerras e, especialmente, sob o regime nazista.

O encolhimento gradativo que nossas instituições democráticas vêm sofrendo, associado aos efeitos da ligação nada republicana entre conservadorismo nos costumes, religião e educação, coloca condições nocivas para a construção de nossos jovens. Tal contexto pode ser comparado ao que adolescentes, como Törless, assistiram nas primeiras décadas do século XX, quando viram a República de Weimar iniciar um processo de erosão em função do totalitarismo crescente também no âmbito da esfera educacional.

A passagem adolescente guarda a interessante possibilidade de o sujeito reinventar um lugar para si no laço social, portanto, na relação com o Outro ${ }^{4}$. Costumamos dizer que a operação psíquica da adolescência produz efeitos ético-políticos na história do sujeito e da cultura porque, justamente, trata-se de advir, por meio dessa operação, a possibilidade de o jovem ler a herança recebida polissemicamente, construindo suas próprias questões a partir da herança que recebeu.

Nesse sentido, perguntamos: qual a possibilidade de que a operação psíquica da adolescência forje um espaço de alteridade e de possibi- 
lidade de construção do novo em um laço social pautado pela demanda de reprodução e ausência de pensamento, como costumam apresentarse os laços em regimes totalitários? Seria a erosão da polissemia nas relações educacionais de regimes totalitários um dos responsáveis pelos jovens sem qualidade que redundam no homem sem qualidade? Ou seja, as vidas sem qualidades que sustentaram o pesadelo nazista e fascista de uma Europa tomada pelos totalitarismos do século XX são tributárias de quais condições educacionais e formativas? Tais perguntas serão tensionadas com fragmentos de $O$ Jovem Törless e algumas nuances de nossa atualidade social e política.

\section{As origens do totalitarismo nas condições educacionais de Törless}

Em História e Psicanálise, Michel de Certeau (2016) argumentou fortemente que a literatura deve ser tomada como a ficção que empresta lógica aos acontecimentos da história, acrescentando que “[...] a literatura cria o não lugar em que as operações efetivas de uma sociedade têm acesso a uma formalização" (p. 92, grifo nosso).

A narrativa literária sobre o jovem Törless evidencia a construção do não lugar, citado por Certeau (2016), que é formalizada pelas páginas da História ao longo do tempo. A fim de operarmos reflexões sobre encaminhamentos para os atuais impasses educacionais, precisamos compreender melhor de que forma o adolescente sem qualidades, forjado no interior dos ateneus militares europeus das décadas que antecederam o nazismo, foi parido como o cidadão sem qualidades disposto a implodir a República de Weimar em prol do $3^{\circ}$ Reich nas décadas que se seguiram - tudo isso descrito em detalhes no clássico de Musil, O homem sem qualidades (publicado originalmente entre 1930-1943), escrito na sequência de Törless (de 1906), como já citado anteriormente.

Para refletirmos sobre os efeitos políticos na constituição dos jovens a partir de Törless - o adolescente típico da Europa do início do século XX que se depara com uma sociedade sem qualidades-e pensarmos sobre a construção educacional com a qual a adolescência de nosso tempo se encontra, precisamos entender melhor as condições sociais e educacionais da Áustria pré-guerras.

As intensas transformações sociais sofridas, na virada do século XIX para o século XX, impôs uma série de complicações à vida nas cidades europeias, dentre elas, a industrialização com seus ritmos frenéticos, o anonimato como forma de vida nas grandes cidades, a dificuldade de conviver com as enormes diferenças sociais implantadas em meio a um crescente ethos voltado ao progresso linear (Benjamin, 1994a). Esse foi o clima propício a teses e concepções educacionais bastante rígidas e conservadoras na direção de comportamentos considerados desviantes. Nesse cenário, cresciam espaços institucionais de formação cada vez mais opressores e autoritários.

Convém lembrar que a Europa desta época - os primeiros anos do século XX - e a Áustria, em especial, começavam a, gradativamen- 
te, militarizar a educação de crianças e jovens. Alguns educadores, já influenciados pelo pensamento freudiano, fizeram forte resistência a esses dispositivos, dentre eles destacamos August Aichhorn (Aichhorn, 2006; Freud, 2012; Gurski; Gus; Moraes, 2016), que, desde as práticas educativas atravessadas pela psicanálise, lutou para que o espírito militar não se apoderasse das instituições.

Não é demais constatar a relação dessa rigidez educativa com as práticas nazistas que vieram na sequência. Vale lembrar que o pai de Daniel Paul Schreber, o Dr. Daniel Gottlieb Moritz Schreber, celebrizou-se como um educador cujas teorias educativas baseavam-se no higienismo, vigor físico e ortopedia. Suas teses rígidas difundiram-se na Europa do século XIX e do início do século XX e foram, inclusive, incorporadas mais tarde pelo nacional-socialismo (Roudinesco; Plon, 1998). Ao encontro dessas teses, os próprios reformatórios, como eram chamadas as instituições que abrigavam os jovens que cometiam atos transgressivos, começavam a mostrar alguns traços compartilhados com a concepção do que viria a ser depois denominado de os totalitarismos do século XX.

Nesse diapasão, o diretor Ingmar Bergman (1977), com a filmagem de O Ovo da Serpente, soube problematizar os efeitos da gravidade da situação econômica e política alemã após a Primeira Guerra Mundial (1914-1918), situação que produziu desemprego, desgoverno e, sobretudo, medo na população. A extrema direita, da então recém-unificada Alemanha, rapidamente aproveitou o caos, produzindo narrativas com efeitos paranoizantes sobre as minorias (Gurski; Pereira, 2019). Foi desse modo que judeus, assim como outros grupos sociais e étnicos considerados estrangeiros, passaram a ser acusados pelo desmonte do país e, por isso, sumariamente perseguidos e vitimados por um plano de extermínio consumado ao longo da Segunda Guerra Mundial (1939-1945).

No filme, Bergman (1977) sugere que o envenenamento progressivo dos laços surge, justamente, da incitação ao ódio, ao racismo e à intolerância. Podemos pensar que, em nossa atualidade, o veneno evocado pelo diretor é o que intoxica os laços, levando a uma autorização tácita da violência com diferentes práticas de extermínio na direção das minorias. Além dessas práticas, que podem ser identificadas como necropolíticas, ou ainda, de acordo com Safatle (2020), como típicas de um estado suicidário ${ }^{5}$, também temos compreendido a política do tiro também é cultura ${ }^{6}$ como um modo de atacar o livre pensar e o agir político no sentido que Arendt dá a essa expressão (Arendt, 2011; 2016).

Constatamos, portanto, a presença de práticas autoritárias e conservadoras no campo educacional e a segregação racial e, tanto em nosso cenário social atual como no contexto da Alemanha convulsionada socialmente das primeiras décadas de 1920, ambiente da adolescência de Törless. Pode-se dizer que a crise econômica e social que assola o Brasil, nestes últimos anos da década de 2010, tem sido atribuída, entre outras questões, ao investimento que teria sido feito, pelos governos anteriores a 2016, nas políticas sociais - ações que foram fundamentais para garantir, por alguns anos, a inclusão social e econômica de sujeitos 
em situação de extrema pobreza e vulnerabilidade social. Nesse sentido, também não se pode esquecer que a produção da intolerância e do preconceito com as minorias tem sido a tônica de políticas conservadoras no País, desde os primórdios do Brasil-colônia.

No período colonial, a sombriedade dos tempos foi vivida pelo exercício de um poder que sempre se colocou à margem da lei, com lugares organizados de modo não estatal, mas como uma espécie de demarcação de zonas de guerra e desordem. A lógica colonial era de que a violência de Estado trabalhava em nome da civilização. A ocupação e a dominação dos espaços se justificavam, na época, porque o outro era o chamado selvagem ou inculto, aquele que estava fora da normatividade civilizada, o que justificava o seu confinamento em um lugar subalternizado e objetalizado. Pensamos que a não transmissão da memória histórica remete ao recalcado de nossa história. Nesse aspecto, poderíamos pensar o afrouxamento da transmissão da história, nos laços educacionais de nossas instituições de formação, como um caminho de autorização tácita às novas configurações de velhas políticas de morte?

Conforme coloca Gambetti (2019), no recente livro Agir em tempos sombrios, precisamos elaborar uma outra crítica aos atuais tempos sombrios. Na esteira de Gambetti, pensamos que uma das reflexões necessárias a serem feitas na direção do novo desejo de fascismo, que se ergue em nossa sociedade, refere-se às práticas educativas como ponto de inflexão fundamental para pensar a dimensão política da constituição da juventude atual. Como criar condições para a produção de jovens com qualidade em um cenário no qual a educação acaba instrumentalizada por um discurso que se esforça em, cada vez mais, achatar a dimensão política da vida? Como produzir diferentes versões e leituras quando a tendência tem sido produzir a univocidade na leitura dos fenômenos e acontecimentos?

\section{A "ausência de qualidades do mundo" de Törless: psicanálise, literatura e Modernidade}

Ilustrado na reflexão de Moretti (2020), o romance de formação tardio sobre o jovem Törless chega praticamente junto com a psicanálise. Törless, o livro de estreia de Musil na literatura, é lançado em 1906, um pouco depois de Freud (2006) escrever Três ensaios sobre a sexualidade, em 1905. O livro de Musil propõe uma interessante condensação entre as questões subjetivas e individuais do jovem e o complexo e turbulento contexto social e histórico em que se desenrola a trama.

Nele, além do tema da sexualidade, o autor explora sua própria experiência (traumática) vivida no interior de um internato austríaco rígido e conservador, cujo ritmo crescente de militarização já denunciava o que estava por vir do ponto de vista político. É nesse ambiente que Törless, o protagonista, mostra-nos as nuances perversas que a tumultuada passagem adolescente, entre o laço familiar e o laço social da época, ofertava à juventude. 
Dentre vários elementos que podem ser examinados no romance, a triste descoberta sobre a ausência de qualidade do mundo em que vivia parece ser a mais importante para Törless. A expectativa da chegada do momento de tornar-se homem, que viria com a vida no internato, longe da família, transformou-se, rapidamente, em um sinistro pesadelo, no qual a melancólica saudade dos pais escondia a frustração com uma vida absolutamente desprovida de qualidades que ele passou a conhecer como perspectiva de futuro.

A narrativa desse romance de formação pode ser tomada como paradigma de uma nova relação da sociedade com a dimensão da passagem do tempo e da transmissão da experiência inaugurada pelas variáveis da Modernidade. As novas condições sociais e culturais lançaram outra atmosfera para a conformação subjetiva e para as etapas da vida. Nas sociedades tradicionais, de transmissão oral, o sentido da vida era vivido no espaço comunitário de modo transcendental, sendo os valores dados a priori pela via da tradição (Benjamin, 1994c). Já no contexto das sociedades modernas, o sujeito passa a se inscrever em uma ordem complexa e abstrata, na qual as filiações simbólicas se perdem, produzindo individualismo, isolamento gradual e a necessidade contumaz de fazer-se representar por si mesmo.

Com um novo quadro de relações sociais, que emerge em concomitância à industrialização da vida e sua consequente aceleração, vivese um distanciamento, cada vez maior, das origens. É como se o sujeito precisasse produzir as relações entre começo, meio e fim, por um fio narrativo mais denso e passível de forjar o enlace, não mais orgânico, entre passado, presente e futuro. Para Benjamin (1994b; 1994c), o filósofo da experiência e do tempo, as mudanças ocorridas ao longo do século XX produziram uma certa erosão na experiência e em seus modos de transmissão, de forma a fazer desaparecer a figura do narrador como representante da tradição oral, surgindo, em seu lugar, o romancista (Kehl, 2001; Gurski, 2012).

É nesse sentido que Kehl (2001) sugere que a narrativa romanesca teve papel preponderante na construção da subjetividade moderna. A psicanalista diz que o romance teve uma grande aceitação social na época, uma espécie de voz do que vinha sendo silenciado: a experiência singular tecida em meio a um laço cada vez menos coletivo.

O historiador e teórico de literatura italiana Franco Moretti (2020), em seu estudo sobre o romance de formação tardio, advoga que, na época, havia um pano de fundo social na direção do livre desenvolvimento do sujeito, o que teria propiciado um cenário, para os jovens, de franco incremento de socialização e crescimento, ou, ainda, de socialização como crescimento individual. Desse modo, o historiador também sugere que o romance, de forma geral, foi uma excelente maneira de libertar o tema da experiência de sua prisão metafísica, abrindo espaço para reconhecermos suas feições.

Nesse contexto, o romance de formação ${ }^{8}$ surgiu no campo literário como o efeito de um certo apagão, na época, dos aspectos formativos 
da educação. A educação clássica, sustentada em valores humanistas desde a Grécia antiga, passava, pouco a pouco, a priorizar aspectos de socialização instrumentais no lugar da formação educativa. É assim que a vida escolar e educacional dos internatos do início do século XX, com suas normas rígidas, parecia anunciar o que estava por vir com as duas grandes guerras, isso, especialmente, nos espaços do já declinante Império austro-húngaro.

Assim como a socialização surge no lugar da formação educativa, advém, no lugar da singularidade da experiência, a ilusão de que a existência se baseia na construção de um destino, tal qual o self-made-man (Kehl, 2001). De tal maneira que, articulando subjetividade e literatura, Benjamin (1994c) sublinha que o romance acabou por representar uma forma de o leitor moderno se aquecer, já que sua vida se tornara gélida e desprovida de sentido por conta da desmoralização da experiência no mundo moderno.

O romance, portanto, assoma como um modo narrativo que se faz necessário como representação imaginária do sujeito moderno que já não se reconhece como pertencente a um laço coletivo. É dessa forma que, sem integrar as formações sociais pré-modernas que conferiam lugares estáveis às vidas que não eram pensadas individualmente, o sujeito freudiano angustiado do início do século XX sintetiza o resultado de décadas de desgarramento contínuo da dimensão coletiva do laço social.

Segundo Kehl (2001), aquele que sorve os romances é um solitário que sofre de compulsão por tudo dizer e que vibra com histórias detalhadas e longas que são justificadas através de muitos dizeres. A Modernidade, ao dispensar a transcendência, elidiu a ideia de um Deus e de um pai, deixando o acervo da linguagem como referência arbitrária de identificação. É nesse contexto que, para Kehl (2001), a subjetividade moderna é feita de muitas palavras, em uma tentativa de compensar a perda de consistência pela erosão da metafísica, gerando a necessidade de o sujeito recriar, a cada dia, tal perda pela via da falação.

A expansão e democratização da literatura, a partir do século XIX, através da difusão de formas ficcionais, produziu todo um outro modo de o homem lidar com seu destino. Nessa conjuntura, surgiram os novos sentidos produzidos em uma sociedade que deixou de ser regida por crenças em uma ordem divina que predeterminava o destino da vida. Foi assim que o romance se tornou o grande estilo literário da Modernidade, fazendo uma ponte entre a solidão do sujeito, que se pensa como autônomo, e as determinações coletivas que ele ignora, mas que não deixam de afetar sua vida privada. Kehl (2001) sugere que a psicologia dos personagens, que é retratada nos romances, em meio às tramas sociais complexas do cotidiano da época, produziu um sujeito da experiência.

É nessa direção que a quebra da unicidade do discurso do Outro, pela via do rompimento com a palavra revelada, trouxe a necessidade de uma fundação própria das escolhas subjetivas. Tal fato culminou no 
apelo a uma rede de interlocuções horizontais capaz de atenuar o desamparo resultante das novas condições sociais.

Essas transformações sociais e subjetivas, além de produzirem mudanças no campo da arte e das expressões humanas, também provocaram uma modificação na relação do homem com a verdade. Os filósofos empiristas, por exemplo, acreditavam que o sujeito só teria acesso à verdade a partir das experiências de seus sentidos, o que significava lidar com a dessacralização da verdade. Na medida em que se perdem as certezas universais e/ou transcendentais, o indivíduo passa a ser o centro de suas referências.

\section{A Antecipação do Sujeito Sem Qualidades na Escrita do Bildungsroman: questões para a adolescência}

Pois será no contexto das transformações sociais e culturais da Modernidade tardia que veremos nascer a adolescência como uma operação psíquica necessária à subjetivação contemporânea. Costuma-se dizer que as sociedades tradicionais não deixavam muito espaço para o tema da escolha. As determinações eram antecipadas, de modo que ao sujeito cabia pouco risco e, portanto, pouco espaço para a escolha. $O$ destino dependia do nascimento e não de uma jornada épica a fim de estabelecer as condições de enunciação próprias. Porém, a partir de variáveis sociais, econômicas, culturais, as sociedades modernas passaram a se organizar em torno de outros referentes, e o tema da liberdade e da autonomia foi adquirindo valor e vigor.

Nesse quadro, as mudanças pubertárias que todo sujeito experimenta ao sair da infância deixaram de ter uma nomeação simbólica consistente. Ruffino (1999) irá dizer que o adolescente contemporâneo sofre especialmente pela impossibilidade de significar as angústias relativas às transformações corporais e psíquicas da passagem adolescente. As curvas, a voz, todo o boom hormonal em face à ausência de ritos de passagem tornaram-se questões da ordem do real $^{9}$, ou seja, situações para as quais o jovem tinha dificuldade de encontrar um modo de elaboração. É como se as mudanças típicas desse período da vida ficassem em um estado traumático para o sujeito. Em diferentes momentos culturais, o social, através dos ritos de passagem, emprestava outros sentidos ao novo que surgia no corpo, situação que, de algum modo, ajudava a aplacar a angústia. Entretanto, na ausência dos ritos de passagem, ou seja, na ausência de um operador simbólico comunitário, o sujeito terá de realizar tal operação de elaboração pela via de uma operação intrapsíquica chamada adolescência (Ruffino, 1999).

A adolescência como crise, com todas as nuances de angústia, nasce com as novas condições da Modernidade. Isto é, em um tempo social no qual cada um deve encontrar um sentido para si e para suas transformações sem o aval coletivo de um rito. É nessa perspectiva que podemos enxergar os sintomas contemporâneos da adolescência como uma resposta, sobretudo, às dificuldades que os jovens de hoje enfrentam para conseguirem se representar no laço social. Essa noção impli- 
ca no fato de o adolescente contemporâneo ser compreendido como o maior representante da crise da Modernidade, quando as estruturas societárias individualistas e não coletivistas perderam a função de simbolização outrora presente em um laço social comunitário.

Essas condições também trouxeram uma necessidade de legitimação dos modos de se fazer representar no âmbito do laço social. Se, antes, as marcas da herança eram suficientes a fim de dar consistência ao lugar do sujeito na cultura, com o advento da Modernidade, essa operação fica prejudicada. Podemos pensar que o surgimento da psicanálise, como dispositivo de legitimidade e autorização da experiência, aproxima-se da operação psíquica da adolescência, pois ambos funcionam como formas de o sujeito realizar individualmente uma operação que outrora era de caráter coletivo.

Nas sociedades tradicionais, a juventude correspondia, primordialmente, a uma diferenciação biológica, porquanto a vida de um jovem seria a exata reprodução da vida dos seus ascendentes. Com a ascensão da burguesia, entra em cena a mobilidade social e a ideia de que é necessário um tempo de formação para a interiorização do mundo, ou seja, trata-se da socialização para uma sociedade em constante transformação. Moretti (2020) localiza também uma mudança simbólica, pois a noção de juventude foi central e antecedente à própria cultura da Modernidade.

O Jovem Törless, de Robert Musil (2003), identificado como um dos romances de formação tardio, revela, justamente, a mudança da passagem da formação, da Bildung, para a socialização moderna e sua relação com os processos de institucionalização. Há, também, na escrita de Musil uma crítica à centralização da socialização no eu e na constituição da sociedade que precisa de indivíduos adaptáveis, normatizados e precários.

Moretti (2020) observa que Freud analisou várias formas literárias, mas não analisou o romance de formação. O autor entende que a psicanálise trabalhou exatamente para demonstrar o jogo de forças e oposições, olhando para o além do eu, enquanto o romance de formação tardio ambicionava construir um eu que interiorizasse as contradições para transformá-las num processo de normalização no qual a ambição de seu herói consistiria sobretudo em ser como todos os outros. Trata-se da narrativa do jovem sujeito da massa que viveu o totalitarismo, os males e soluções extremas nos quais as instituições são fortes e os indivíduos são frágeis.

O romance de formação tardio mostra aspectos da subjetivação adolescente discutidos à luz de questões éticas, sociais e políticas. O livro sobre o jovem Törless inicia-se com os pais levando-o para o internato de ordem religiosa onde deveria iniciar sua formação. O narrador, logo de início, revela que a Sra. Törless aceitou a separação do filho e sua ida para a escola para "proteger a juventude das influências corruptoras de uma grande cidade” (Musil, 2003, p. 8). O próprio Törless aceita a ideia da ida para o internato "até com prazer" (p. 9) para poder 
afastar-se da família e fazer sua passagem rumo ao que acreditava ser a adultez. Entretanto, a alegria inicial com a separação transformou-se em uma espécie de melancolia, na qual ele se sente tomado por uma “sensação de vazio" (p. 9), vendo o mundo exterior como um lugar triste, monótono e inabitável.

\section{Entre o Educar e o Socializar: questões ético-políticas em tempos sombrios}

A sensação de vazio e a própria solidão adolescente chega como efeito do encontro com a dimensão da falta e da não completude (Rassial, 1999). Nesse sentido, o começo do romance ilustra bem o grande trabalho psíquico da adolescência; operar a castração do Outro da infância, ou, dito de outro modo, fazer a passagem do laço familiar para o laço social. Conforme se vê nos desejos iniciais de separar-se dos pais, Törless mostra que a relação com as figuras de autoridade começa a perder consistência, é aquilo que Rassial (1999) chamará de a pane do Outro, momento no qual o jovem se depara com a falta em sua dimensão simbólica. Para Törless, ir para o internato representava, na verdade, a possibilidade de ter um espaço seu, longe da família, um tempo para construir seu lugar de fala e para dar conta de suas origens de um outro modo que não pela via do romance familiar.

O encontro com a dimensão da falta do Outro é responsável pela própria operação psíquica da adolescência, quando o sujeito tem condição de trocar a posição infantil, de crença em uma completude imaginária e para sempre perdida, pela noção da falta estrutural.

Essa questão estrutural da constituição referida acima torna-se interessante quando refletimos sobre o contexto social e político da época da concepção de Törless. Os anos iniciais do século XX foram responsáveis pelo derretimento gradativo das ilusões iluministas no campo da cultura e progressistas no âmbito da política, momento em que as instituições tradicionais, tais como a Igreja e o exército, encontravamse empoderadas e os líderes tomados por feições cada vez mais totalitárias, jogando os sujeitos em uma angustiante sensação de fragilidade.

Lacan, no Seminário 15 (1967-1968/s. d.), sublinhou a importância do ato do analista por este demarcar uma diferença com o simples fazer. O ponto de corte do ato analítico reside exatamente na posição ética de romper com a posição de mestre (S1), recusando a totalidade. A recusa da totalidade é o que forja potência e vivacidade à visão polissêmica das condições que se colocam para os sujeitos. Por esse prisma, podemos dizer que resistir à tirania do UM e viabilizar modos de o sujeito não se curvar a nenhuma totalidade do Outro é uma das tarefas da educação atravessada pela dimensão do sujeito (Gurski, 2017).

Entendemos que, através das nuances da vida de Törless, Musil (2003) problematizou os caminhos formativos de uma sociedade cada vez menos afeita à presença do sujeito e do desejo. Não à toa, Musil, no romance, mostra os trágicos destinos do cruzamento dos caminhos da 
sexualidade, da violência e da socialização na vida dos adolescentes do internato.

Os jovens dos romances tardios de formação revelam que a lógica do desejo e a primazia do sujeito se desfazem em nome das instituições sociais de inclinação totalitária, questão que, mais tarde, aparecerá com materialidade na formação da juventude hitlerista. É desse modo que a socialização da época, como dimensão de alienação à demanda do Outro social, operou fazendo resistência ao despertar da adolescência como movimento de diferenciação da demanda do Outro. A guerra civil que habitava o interior pulsional dos jovens, no tempo social de Törless, foi enfrentada com a construção de um horizonte totalitário e estático.

Nos novos fascismos, a geração que não conheceu o totalitarismo do século passado professa o pragmatismo extremo - eles entendem tal pragmatismo como uma virtude, posto que são ações sem ideologia. As escolhas dependem de redes sociais e pesquisas de opinião, desacreditando qualquer valor que não o hiperindividualismo. É também o pragmatismo despolitizado que não vê diferença entre esquerda e direita porque vale somente a opção que funciona melhor. Podemos pensar que isso se assemelha ao princípio da TINA (There Is No Alternative) ${ }^{10}$, através do qual se internaliza a noção de que não há alternativa ao totalitarismo das leis do mercado, do capitalismo, do neoliberalismo e da globalização.

Nesse sentido é que a discussão sobre o jovem sem qualidades se aproxima do que estamos vivendo. Ulrich, o protagonista do romance O Homem sem Qualidades, poderia ser pensado como o futuro adulto de Törless. Ambos, cada um em sua fase, vivem uma vida massificada, cujas condições simplificadas e pragmáticas acerca das relações originam um manancial de preconceitos como modo de lidar com o outro. $\mathrm{O}$ jovem e o homem sem qualidades de Musil, assim como o(s) nosso(s), são uma espécie de instrumentos de práticas totalitárias que visam ao apagamento de qualquer manifestação crítica. Uma de suas operações da máquina totalitária se dá pela via da simplificação de valores e de conceitos que leva a uma espécie de naturalização dos conflitos, assim como a uma redução do pensamento e da mobilização de autonomia política. A sequência do romance inacabado de Musil foi a produção de sujeitos capazes de gestar as atrocidades da Segunda Guerra Mundial.

Essas questões aparecem nas interrogações e dramas de Törless. $\mathrm{O}$ adolescente estabelece um questionamento ético aos seus colegas Reiting e Beineberg; no início, questiona os atos dos colegas, porém, na sequência, vemos que a relação entre os três revela a erotização do poder como um interesse maior que o prazer. Podemos dizer que essa é a conclusão adicional que Musil (2003) acrescenta ao romance, em que vemos a restauração da imagem positiva dos pais e, também, da classe burguesa. Em certo momento, Törless escreve uma carta instrucional a Basini ${ }^{11}$ pedindo que ele reconheça o roubo, relembrando a carta de seus pais e assumindo uma posição de superioridade, através da qual rejeita as experiências sociais e sexuais vividas no internato. 
Moretti (2020) assinala que o adulto Törless encarna uma solução imaginária, reconciliando duas realidades nas quais a Modernidade força o sujeito a viver simultaneamente: o mundo exterior, no qual deve se objetivar para encontrar o seu lugar na ordem social, e o mundo interior, aparentemente livre, no qual o sujeito pode desempenhar sua individualidade. Talvez esse fragmento simbolize o Bildungsroman no seu registro irônico: não há conflito entre individualidade e socialização, autonomia e normalidade, interioridade e objetivação. A formação de um indivíduo coincide sem brechas com a integração social de alguém como parte simples de um todo.

Em uma das últimas frases, o narrador incentiva o leitor a reconhecer o significado da formação de Törless. Ele é descrito como um homem que possui uma sensibilidade suficientemente sofisticada para experimentar autodeterminação e gratificação estética em qualquer lugar do mundo, um adulto adaptado à realidade de seu tempo e da sua sociedade.

No entanto, a ironia do narrador, nesse momento final, indica a mudança do sentido do romance de formação e a tarefa impossível da Modernidade, especialmente para um adolescente: tornar-se um indivíduo, uma totalidade em um mundo absolutamente fragmentado e violento. O narrador do romance insiste no sucesso da educação de Törless e declara que "Uma fase se encerrara, a alma formara mais um anel, como na casca de uma árvore jovem. Essa sensação poderosa, para a qual não havia palavras, desculpava tudo o que acontecera" (Musil, 2003, p. 147). É assim que o adulto Törless concorda de todo o coração e garante ao leitor que "não se arrependeu do que fizera" (p. 147). A necessidade de garantir ao leitor sua socialização exemplar, justificando todos os eventos da novela, levanta a pergunta: por que Törless precisa dar tantas garantias à socialização?

O desejo de explorar o mundo sombrio da transgressão e da violência não desapareceu, mas Törless retornou para o mundo vazio do início do romance, pois os ideais progressistas do antigo mundo estavam perdidos. Melancolicamente, podemos inferir que Törless amadurecerá na obra de Musil como Ulrich, o homem sem qualidades do grande escrito inacabado de Musil (1989) - que, de algum modo, antecipa, na literatura, o conceito magistral de banalidade do mal, cunhado por Hannah Arendt (1999) em meio à cobertura do julgamento de Eichmann em Israel. É de Ulrich o dito "[...] o ser humano, com efeito, tanto pode comer outros homens como escrever a Crítica da Razão Pura; com as mesmas convicções e as mesmas qualidades” (Musil, 1989, p. 57).

Essas transformações foram um catalisador para o desastre. Os recursos da civilização, sintetizados pela fé na racionalidade, na lei moral e no progresso, foram escavados por dentro; sem peso, logo perderam a capacidade de resistir à barbárie que se precipitou em todos os lugares, inclusive nas vicissitudes da adolescência.

Lacadée (2011), em $O$ despertar e o exílio, ao comentar o romance de formação de Musil, destaca como a eliminação de um outro pode 
tornar-se mesmo uma solução. Ele comenta, de forma crítica, a postura de Beineberg, um dos colegas de Törless, quando diz que Basini nada significa para ele e que humilhá-lo, aniquilá-lo, seria uma coisa boa, uma espécie de purificação.

O contexto social e político da adolescência de Törless nos induz a pensar na sua dificuldade em reinventar-se, de construir um saber-fazer com seu sinthome ${ }^{12}$, assumindo a dose de singularidade necessária a fim de responder pelo seu lugar em uma posição de alteridade na relação com o Outro, tarefa da operação psíquica da adolescência. Se tal operação, que evoca a singularidade e, portanto, o novo da inscrição do sujeito no laço social, fosse possibilitada pelas condições da época, talvez Musil não tivesse levado o jovem Törless à posição do homem sem qualidades em seu romance da maturidade. Por conseguinte, parece que foi sem acidente que o nazismo e outros movimentos extremos ganharam espaço nesse ambiente destituído de maiores qualidades.

\section{Psicanálise, Educação e Política: enlaces para um novo futuro}

A narrativa sobre a formação de Törless evoca a articulação da discussão da psicanálise com a adolescência e as relações de poder, questões que são centrais para a constituição dos jovens e para o momento histórico atual. Os textos freudianos sobre a cultura e política abordaram exatamente a guerra, a morte e o laço social articulados com os temas da dominação, do poder, da submissão e da violência.

Na discussão deste escrito, em que evocamos a noção de formação e o seu desaparecimento do horizonte histórico em favor de uma socialização instrumental, destacamos que nos preocupa a neutralização da questão mais importante da operação adolescente, a produção do novo do sujeito, a dimensão singular de sua criação que toma forma na passagem adolescente e que coloca o jovem em posição de forjar algo novo para a cultura de seu tempo. Preocupa-nos porque vemos que a dimensão impessoal da socialização, fomentada pelas instituições educativas atuais, tornou quase impossível para os adolescentes a sustentação de outro lugar discursivo, passível de produzir mudança social e não apenas adequação e/ou reprodução das normas. Conforme já afirmamos, um dos elementos que desestabilizou a narrativa de formação foi o descobrimento do inconsciente, pois o pensamento freudiano estabeleceu uma ligação entre o conceito moderno de alienação e o sofrimento imposto pelo processo de socialização. A alienação e a socialização do desejo foram pensadas, por Freud (2010), como unidos entre si, um modo de produção de identidades e internalização de normas. Posteriormente, autores pertencentes à Escola de Frankfurt, como Adorno e Horkheimer (2000), articularam, a partir da Teoria Crítica, os modos de sofrimento com a economia psíquica e a ordem social, refletindo sobre aspectos do fascismo e do autoritarismo.

No Brasil, a partir dos anos 1990, com a redemocratização do País, tivemos mudanças no sistema educacional, impulsionadas por altera- 
ções nas agendas de pesquisa universitárias, que modelaram novas políticas públicas de educação. As instituições educacionais começaram a discutir a ideia da diferença e não apenas da diversidade. Talvez esses anos de reconstrução da democracia nacional tenham ajudado no esboço de uma posição mais participativa da juventude brasileira no cenário social. Tivemos alguns movimentos, tais como os protestos de 2013, que recolocaram os jovens como atores sociais mais ativos, conclamando seu protagonismo e mobilizando a esperança, mas, também, reascendendo os temores típicos de uma sociedade conservadora.

Nesse cenário de giro na educação e na posição das novas gerações, tivemos também o ressurgimento e ascensão da extrema-direita no Brasil. As lideranças conservadoras e extremistas localizaram a educação como o principal elemento de desordem a carecer de uma intervenção purificadora em função da ameaça que representava às referências valorativas da sociedade brasileira: a família, a religião e até mesmo as formas de relacionamento amoroso e sexual.

Através de pautas educacionais, tais como a escola sem partido, a homeschooling e as escolas militarizadas, assistimos ao retorno de uma concepção de socialização no lugar da educação. Pensamos que, da mesma forma como em Törless, esse incremento de individualidades não se dirige à construção coletiva, tampouco à construção da paz e do convívio. A expectativa é por um líder semelhante ao Pai da horda que restabeleça uma ordem que nunca existiu e que purifique, com incitação ao ódio, os desviantes e diferentes. Tal como Törless, os mentores dos atuais rumos educacionais se pautam pelo que temos chamado de desejo de fascismo (Gambetti, 2019; Perrone; Gurski; Gambetti, 2019; Gurski; Perrone, 2020).

A problematização que estamos discutindo foi sintetizada no novo projeto educacional do governo: o Programa Nacional das Escolas Cívico-Militares, cuja proposta é de que, sob a gestão militar, o problema da violência juvenil será solucionado. Pela via dessa concepção, as regras e disciplinas, no ambiente escolar, serão responsáveis por aumentar naturalmente o desempenho dos alunos.

A nova escola proposta pela lógica da militarização alia-se à outra política do passado brasileiro, a criminalização da pobreza. Tal lógica questiona as estruturas e ganhos democráticos da educação nas últimas décadas, utilizando o discurso do medo, da exceção e da ameaça. É importante também referir que a militarização das escolas públicas significa a desconstrução da luta pelo direito à educação pública e que sua ruína pública também é o desfazimento do Estado, dos direitos e da cidadania.

Nessa mesma direção de diluição do Estado democrático, está o projeto que pretende dar direito à chamada educação familiar. Nesse Projeto, a criança e o jovem não são pensados como cidadãos, como sujeito de direitos com a garantia de uma educação pública de qualidade fornecida pelo Estado, a educação pública se transforma em uma socialização militarizada, em que o principal é a soberania da pátria, 
da regra, da disciplina e de uma determinada ordem. Desse modo, os corpos políticos de crianças e jovens são pensados não a partir das suas singularidades, mas, sim, desde a busca da massificação e homogeneização. Trata-se da antítese de um paradigma educacional que considera a dimensão da singularidade do sujeito e do desejo.

A pauta neoliberal aliou-se ao conservadorismo moral, na contramão do processo democratizador que ocorria no País. Nesse diapasão, o desejo de fascismo evoca o uno a partir do múltiplo e busca eliminar qualquer possibilidade de ação. A vontade humana desaparece para transformar qualquer um na velha dobradinha de vítima e carrasco, como acompanhamos no romance de formação de Musil (2003). Pensamos que, diante da adolescência sem qualidades que se forja em um mundo de relações pouco qualificadas, cabe um trabalho de restauração e composição histórica dos desejos dos sujeitos, uma proposta que possa articular presente, passado e futuro, de modo que os jovens sejam capazes de forjar uma versão própria e singular de sua passagem pelo mundo. Uma passagem que não seja simplesmente uma repetição ecolálica do que receberam.

Recebido em 12 de novembro de 2020 Aprovado em 19 de fevereiro de 2021

\section{Notas}

1 O livro foi considerado como romance de formação tardio. Ele narra episódios de três estudantes, Reiting, Beineber e Törless, em um internato militar austríaco do início do século XX. O trio, após descobrir um roubo do colega Basini, decide puni-lo, ao invés de denunciá-lo às autoridades do colégio. A punição se dá através de abusos físicos, psicológicos e sexuais do adolescente. Ao longo do romance, aparecem questões sobre a sexualidade dos adolescentes, dramas éticos e comportamentos compulsivos. Quando a tortura do trio passa dos limites morais suportados por Törless, ele secretamente aconselha Basini a se entregar para o diretor, como uma forma de sair da situação. Ao final, Törless retorna à casa dos pais e sua educação é finalizada.

2 Referimo-nos ao livro O homem sem qualidades de Robert Musil (Ed. Nova Fronteira, 1989). O livro é considerado uma das principais obras da literatura do século XX, ambientado na Viena do pós-primeira guerra.

3 Para outros detalhes sobre o sentido do despertar da primavera para a psicanálise com adolescentes, ver Lacan (2003).

4 Em sua obra, Lacan formulou diferentes desdobramentos sobre a noção de Outro (A), Autre em francês. Uma dessas facetas refere-se ao (grande) Outro como lugar de alteridade radical que se apresenta ao (pequeno) outro (a) - nosso semelhante com quem mantemos uma relação de identificação através da especularidade imaginária (Lacan, 2010). Nessa via, o Outro também pode ser pensado no âmbito dos discursos que existem além e aquém de nós mesmos e que nos constituem como seres de linguagem.

5 O filósofo francês Paul Virilio (1999 apud Safatle, 2020) desenvolveu o conceito de estado suicidário como o inevitável desfecho final de todos os Estados que têm o desenvolvimento técnico e o progresso econômico como elementos principais de sua existência. É suicida na medida em que exaure seus próprios 
recursos naturais e humanos, reproduzindo a lógica da busca infindável pelo aumento da produção e do consumo para atender a uma estrutura de mercado econômica neoliberal. Dessa forma, o Estado suicidário é "um novo estágio do Estado nos moldes de gestão imanentes ao neoliberalismo. É, portanto, sua fase terminal" (Safatle, 2020). O conceito de Estado suicida/suicidário não foi criado para caracterizar, especificamente, Estados fascistas, porém há intrínsecas correlações entre os Estados fascistas do século XX e o Estado suicidário: podemos associar o Estado suicidário à característica de regimes fascistas que remetem ao heroísmo e ao culto da (própria) morte. No fascismo, essa aproximação com seu próprio fim relaciona-se ao indivíduo (ego) e, no Estado suicidário, ao próprio corpo estatal.

6 Expressão utilizada pelo deputado Eduardo Bolsonaro em novembro de 2020. Para mais informações, ver: https://istoe.com.br/eduardo-bolsonaro-faz-aulano-bope-com-mario-frias-e-diz-que-tiro-tambem-e-cultura/

7 Para Arendt a ação política é sempre coletiva, por mais que comece com um indivíduo; ela é uma relação, existe entre iguais e garante um mundo plural. Ao agir politicamente, o indivíduo deve se debruçar sobre a realidade e agir entre outros, mantendo os significados recuperados do passado para elaborar conceitos e valores que garantam o agir cotidiano.

8 O romance de formação apresenta a formação de um jovem protagonista através de suas experiências, viagens, conquistas e desilusões; a narrativa trata do desenvolvimento individual e da integração em uma sociedade como duas faces de um percurso histórico. Gradativamente, a partir das revoluções burguesas, o pragmatismo se impõe e a dimensão da formação perde o sentido na sociedade de massas, sendo substituída pela dimensão da socialização educativa.

9 Instância que constitui um dos três registros que, junto ao simbólico e ao imaginário, fundam o que Lacan denominou de RSI. Esses são registros indissociáveis, ligados pelo nó borromeu, que dão conta da relação do sujeito com a dimensão da falta. Para Lacan, o real é o que não pode ser simbolizado totalmente pela palavra, aquilo que "não para de não se escrever" (Lacan, 1985, p. 127).

10 Slogan político atribuído a Margaret Thatcher.

11 Cf. Nota 1.

12 Saber-fazer com o sinthome seria o equivalente ao momento em que o sujeito adolescente aceita tomar nas mãos a aventura de uma reinvenção de si a partir das marcas originais do que recebeu como herança e transmissão. Momento em que opera uma escolha subjetiva, autorizando-se a fazer uma versão própria do herdado. Para mais informações, ver Gurski (2017).

\section{Referências}

ADORNO, Theodor; HORKHEIMER, Max. Dialética do esclarecimento. Rio de Janeiro: Jorge Zahar, 2000.

AICHHORN, August. Juventud desamparada. Barcelona: Gedisa, 2006. (Publicado originalmente em 1925).

ARENDT, Hannah. Eichmann em Jerusalém: um relato sobre a banalidade do mal. São Paulo: Companhia das Letras, 1999.

ARENDT, Hannah. Entre o passado e o futuro. São Paulo: Perspectiva, 2011. 
O Jovem ‘Sem Qualidades’ e o Desejo de Fascismo

ARENDT, Hannah. A condição humana. Rio de Janeiro: Forense Universitária, 2016.

BENJAMIN, Walter. Magia, Técnica, Arte e Política. Obras Escolhidas I. São Paulo: Brasiliense, 1994a.

BENJAMIN, Walter. Experiência e Pobreza. In: BENJAMIN, Walter. Magia, Técnica, Arte e Política. Obras Escolhidas I. São Paulo: Brasiliense, 1994b. P. 114119. (Publicado originalmente em 1933).

BENJAMIN, Walter. O Narrador. In: BENJAMIN, Walter. Magia, Técnica, Arte e Política. Obras Escolhidas I. São Paulo: Brasiliense, 1994c. P. 197-221. (Publicado originalmente em 1936).

CERTEAU, Michel de. História e psicanálise: entre ciência e ficção. Belo Horizonte: Autêntica Editora, 2016.

FREUD, Sigmund. Três ensaios sobre a teoria da sexualidade. In: FREUD, Sigmund. Edição Standard Brasileira das Obras Psicológicas Completas de Sigmund Freud. v. 7. Rio de Janeiro: Imago, 2006. (Publicado originalmente em 1905).

FREUD, Sigmund. O mal-estar na civilização. In: FREUD, Sigmund. Obras Completas. v. 18. São Paulo: Companhia das Letras, 2010. (Publicado originalmente em 1930).

FREUD, Sigmund. Prólogo a juventude abandonada, de Aichhorn. In: FREUD, Sigmund. Obras Completas. v. 16. São Paulo: Companhia das Letras, 2012. (Publicado originalmente em 1925).

GAMBETTI, Zeynep. Agir em Tempos Sombrios. Porto Alegre: Editora Criação Humana, 2019.

GURSKI, Rose. Três ensaios sobre juventude e violência. São Paulo: Escuta, 2012.

GURSKI, Rose. Os novos sintomas na educação de hoje: notas sobre o saberfazer com isso. In: PEREIRA, Marcelo (Org.). Os sintomas na educação de hoje: o que fazemos com isso? Belo Horizonte: Scriptum, 2017.

GURSKI, Rose; GOMES, Paula; MORAES, Larissa. Aichhorn: uma obra abandonada?. SIG: Revista de Psicanálise, Porto Alegre, v. 5, p. 63-72, 2016.

GURSKI, Rose; PEREIRA, Marcelo Ricardo. Apresentação. Psicanálise e socioeducação: efeitos de um encontro. In: GURSKI, Rose; PEREIRA, Marcelo Ricardo (Org.). Quando a psicanálise escuta a socioeducação. Belo Horizonte: Fino Traço, 2019. P. 17-26.

GURSKI, Rose; PERRONE, Cláudia. COVID-19: A Brake on the Desire for Fascism in Brazil. Critical Times: Interventions in Global Critical Theory, Berkeley, May 11, 2020. Disponível em: <https://ctjournal.org/2020/05/11/covid-19-and-thewaning-of-the-desire-for-fascism-in-brazil/>. Acesso em: 02 set. 2020.

HANKE, Michael. A qualidade de 'O homem sem qualidades' de Robert Musil. Revista Alceu, v. 4, n. 8, jan./jun. 2004.

KEHL, Maria Rita. Minha vida daria um romance. In: BARTUCCI, Giovanna (Org.). Psicanálise, literatura e estéticas de subjetivação. Rio de Janeiro: Imago, 2001. P. 57-89.

LACADÉE, Philippe. O despertar e o exílio: ensinamentos psicanalíticos da mais delicada das transições, a adolescência. Rio de Janeiro: Contra Capa Livraria, 2011.

LACAN, Jacques. O Seminário, livro 15: sobre o ato psicanalítico. [S.l.]: [S. d.]. (Versão Inédita). (Publicado originalmente em 1967-1968). 
LACAN, Jacques. O Seminário 20: mais, ainda. Rio de Janeiro: Zahar, 1985. (Publicado originalmente em 1972-73).

LACAN, Jacques. Prefácio a O despertar da primavera. In: LACAN, Jacques. Outros Escritos. Rio de Janeiro: Jorge Zahar, 2003. P. 557-559. (Publicado originalmente em 1974).

LACAN, Jacques. O Seminário, livro 2: o eu na teoria de Freud e na técnica da psicanálise. Rio de Janeiro: Jorge Zahar, 2010. (Publicado originalmente em 1954-55).

MORETTI, Franco. O Romance de Formação [formato ebook]. São Paulo: Todavia, 2020. (Publicado originalmente em 1987).

MUSIL, Robert. O homem sem qualidades. Rio de Janeiro: Nova Fronteira, 1989. MUSIL, Robert. O jovem Törless. Rio de Janeiro: Nova Fronteira, 2003. (Publicado originalmente em 1906).

OVO da Serpente, O. Direção: Ingmar Bergman. Produção: Dino De Laurentiis Company; Rialto Film. Alemanha; Estados Unidos, 1977. (119 min.).

PERRONE, Cláudia; GURSKI, Rose; GAMBETTI, Zeynep. Os novos fascismos e a oniropolítica. Projeto de Pesquisa. Porto Alegre: UFRGS, 2019. 36 f.

RASSIAL, Jean-Jacques. $\mathbf{O}$ adolescente e o psicanalista. Rio de Janeiro: Companhia de Freud, 1999 .

ROUDINESCO, Elisabeth; PLON, Michel. Dicionário de Psicanálise. Rio de Janeiro: Jorge Zahar, 1998.

RUFFINO, Rodolpho. Fazendo Valer - Modalidade Contemporânea. In: ASSOCIAÇÃO PSICANALÍTICA DE PORTO ALEGRE (Org.). Adolescência: entre o passado e o futuro. Porto Alegre: Artes e Ofícios, 1999. P. 291-314.

SAFATLE, Vladimir. Bem-vindo ao Estado suicidário. São Paulo: n-1 Edições, 2020

Rose Gurski é doutora em Educação pela Universidade Federal do Rio Grande do Sul (UFRGS). Professora do Departamento de Psicanálise e Psicopatologia, do PPG Psicanálise: Clínica e Cultura (UFRGS) e do PPG Psicologia Clínica (USP). Vice-Coordenadora do Núcleo de Pesquisa em Psicanálise, Educação e Cultura (NUPPEC/UFRGS). Pesquisadora associada do PSOPOL (USP). Pós-doutoranda IPUSP.

ORCID: http://orcid.org/0000-0002-7392-1463

E-mail: rosegurski@ufrgs.br

Cláudia Maria Perrone é professora do Departamento de Psicanálise e Psicopatologia e do PPG Psicanálise: Clínica e Cultura da Universidade Federal do Rio Grande do Sul (UFRGS). Coordenadora do Eixo 3 do Núcleo de Pesquisa em Psicanálise, Educação e Cultura (NUPPEC/UFRGS).

ORCID: http://orcid.org/0000-0002-3840-4575

E-mail: cmperrone@ig.com.br

Editora-responsável: Fabiana de Amorim Marcello

Este é um artigo de acesso aberto distribuído sob os termos de uma Licença Creative Commons Atribuição 4.0 Internacional. Disponível em: <http:// creativecommons.org/licenses/by/4.0>. 